\begin{tabular}{|c|c|c|}
\hline fowand ont & $\begin{array}{c}\text { Gazi University } \\
\text { Journal of Science }\end{array}$ & 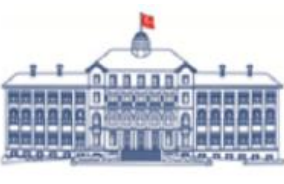 \\
\hline & http://dergipark.gov.tr/gujs & \\
\hline
\end{tabular}

\title{
A Fuzzy Logic Approach on the Evaluation of Driving Styles and Investigation of Drivability Calibration Effects
}

\author{
Samet AKSIT ${ }^{1}$, Akif YAVUZ ${ }^{2}$, Osman Taha SEN ${ }^{2, *}$ (D) \\ ${ }^{1} A V L$ Turkey Research and Engineering, 34885 Istanbul, Turkey \\ ${ }^{2}$ Istanbul Technical University, Faculty of Mechanical Engineering, 34437, Istanbul, Turkey
}

\author{
Highlights \\ - This paper investigates the effect of drivability calibration on the driving style of the driver. \\ - A fuzzy logic approach is implemented in order to evaluate the driver behavior. \\ - An automated driver classification algorithm is proposed based on experimental data.
}

\section{Article Info}

Received: 17 Jan 2021 Accepted: 31 July 2021

\section{Keywords}

Drivability calibration Fuzzy logic algorithm Driver classification

\begin{abstract}
Increased customer expectations lead the automobile manufacturers to develop innovative solutions, such as mode selection functions that provide different performance and comfort settings for the drivers. Almost all brands have different types of driving modes installed on their vehicles, such as sport mode, economy mode, off-road mode, etc. In the current technology, the mode selection is manually done by the driver. Thus, no effort is taken to match the driver style with available driving modes. However, driving mode selection should be done through an intelligent system such as vehicle control unit, in order to optimize customer expectations related to vehicle performance, driving comfort, and fuel consumption. This can be achieved by the analysis of all drivability maneuvers during any driving cycle. Based on the results of these analyses, drivability calibration settings of the vehicle can be adjusted depending on driver behaviors. In addition, fuel consumption can be improved using suitable calibration for each driver type. In this study, an experimental investigation is carried out in which vehicle data is collected for eleven different drivers at three different drivability calibrations. Furthermore, fuzzy logic algorithms are utilized in order to distinguish the driver characteristics. First, data from nine drivers are used in order to train the fuzzy logic approach. Then, the trained fuzzy logic scheme is used to assess the characteristics of two other drivers, who were left out in the training data set. Hence, it is aimed to obtain an intelligent prediction procedure that can estimate the characteristics of a driver based on their driving styles.
\end{abstract}

\section{INTRODUCTION}

Performance of a vehicle, which is closely related with the acceleration perception, and driving comfort are two key parameters for customer satisfaction. However, there is a trade of between these two criteria, i.e., an increase in acceleration performance can disturb the driving comfort and any attempt taken to improve driving comfort may lead to a decrease in the acceleration performance. In automotive technology, the acceleration performance and driving comfort characteristics of a vehicle determine its drivability, which can be described as the smoothness of the vehicle motion and perception of performance. Furthermore, all dynamic maneuvers of a vehicle are controlled by drivability functions, which are acceleration, deceleration, gear shifting, launch maneuvers, etc. Note that the engine and transmission dynamics have an important effect on drivability characteristics of the vehicle, which are controlled by the vehicle control unit (VCU). Hence, one can assure that the drivability characteristics of the vehicle would be satisfactory if the VCU is properly calibrated. 
Maneuvers such as tip-in and tip-out, which are sudden push or release of the acceleration pedal, lead to oscillations in transmission that would be hard to suppress through structural modifications. Though, proper control of driver behavior effects on drivetrain can prevent these vibratory responses easily. However, filtering the driver request would not be an effective solution, since these limitations can cause a decline in acceleration performance. Hence, calibrating the drivability functions is an important task that is essentially finding the optimal settings for the control of torque and its transition from engine to wheel, while keeping the acceleration performance and driving comfort at satisfactory levels. These optimal parameters are usually determined by the manufacturer as a part of the development process and cannot be altered during the operation of the vehicle.

Classification of drivers and understanding their expectations from the vehicles is an important task for vehicle manufacturers. Hence, detailed experimental studies related to this objective have been conducted. In these studies, experiments have been conveyed in three different testing environments: 1) simulation platforms [1-3]; 2) model-based test platforms [4,5]; and 3) real vehicle tests [6-10]. Furthermore; fuzzy logic [11], neural network method [12] and machine learning [6] are some of the approaches that have been applied for the classification of drivers. Though none of these studies investigated drivability calibration effects on driving behavior. In addition, literature studies generally involve three input parameters for classification such as acceleration, velocity and fuel consumption [7,11-15]. In this study, seven parameters have been assumed to be inputs for the fuzzy logic algorithm, which is utilized for driver evaluation.

The chief objective of this study is to develop a driver evaluation algorithm by using fuzzy logic approach. Hence the objectives of this study can be listed as: 1) to create a driving cycle on which the tests are conducted; 2) to develop three different drivability calibrations for the vehicle that is used in the experiments and collect driving data from eleven drivers at each calibration; 3) to identify necessary fuzzy logic membership functions for all drivability calibrations and create fuzzy logic rules, accordingly; 4) to generate a fuzzy logic prediction algorithm and investigate collected data with this algorithm in order to evaluate driver behavior; and 5) to investigate the effect of drivability calibration on driving style.

\section{DRIVING STYLE CLASSIFICATION AND DRIVABILITY CALIBRATION EFFECTS BASED ON EXPERIMENTAL DATA}

In this study, driver evaluation is performed with the use of experimental data. As mentioned before, experiments have been conducted on a vehicle at three different drivability calibrations by eleven different drivers. Hence, a light duty vehicle with 2.0 liter diesel engine equipped with a manual transmission is utilized. The vehicle has a total mass of $2950 \mathrm{~kg}$ and the maximum power of the engine is $125 \mathrm{~kW}$.

\subsection{Experimental Procedure}

Data is collected on a public road, though the route is kept intact for all drivers. Furthermore, all tests were performed on the weekdays during the hours 11:00 - 15:00 in order to avoid high traffic jam, ambient temperature variations and pedestrian activities. The test path is selected accordingly, so that a speed range of $0-100 \mathrm{~km} / \mathrm{h}$ can be achieved. Furthermore, the path that is $10.2 \mathrm{~km}$ long allows drivers to perform different maneuvers such as deceleration, acceleration, gear shifting, launching, etc.

Drivers are selected depending on their driving experience, i.e., minimum of two years of experience is sought. Eleven drivers have been asked to drive the vehicle three times, in each only the drivability calibration is changed. Thus 33 runs are performed and data is collected accordingly.

The drivability calibrations developed in this study are labelled as relax, normal and aggressive. These calibrations are obtained by altering several VCU settings such as torque request characteristics, torque ramp limits, additional torque requests for launch maneuver, additional engine speed request for gearshift maneuvers. Details of these drivability calibrations are tabulated in Table 1. 
Table 1. Three drivability calibrations and levels of corresponding characteristics

\begin{tabular}{|c|c|c|c|c|}
\hline Calibration & Torque Request & Torque Ramp & $\begin{array}{c}\text { Additional Torque } \\
\text { Request on Launch }\end{array}$ & $\begin{array}{c}\text { Additional Engine } \\
\text { Speed on Gear Shift }\end{array}$ \\
\hline Relax & Low & Low & Low & Low \\
\hline Normal & Medium & Medium & Medium & Medium \\
\hline Aggressive & High & High & High & High \\
\hline
\end{tabular}

Data during tests are collected with a $10 \mathrm{~Hz}$ sampling rate and collected data is investigated in time domain. First, the idling maneuvers are extracted from the raw data. Then, the mean values for acceleration, fuel consumption, engine speed, acceleration pedal position and speed are evaluated with a moving average filter, where the window and data size are taken as 9 and 6, respectively as also recommended by Murphey et al. [1].

\subsection{Test Data Evaluation}

In this study, the driving styles are analyzed with seven parameters, which are extracted from the data collected during the tests. These parameters are: 1) vehicle speed;2) vehicle acceleration; 3) engine speed; 4) acceleration pedal position; 5) fuel consumption; 6) engine speed at gear shifting instance and 7) launch time. Among these data, vehicle speed, vehicle acceleration, engine speed and acceleration pedal position are directly obtained from the CAN bus of the vehicle. However, the other parameters are calculated from the relevant measured data.

Total fuel consumption $F_{t y}$ is one of these calculated data by the time-based fuel consumption information available from CAN bus. The calculation is performed as shown with Equation (1), where $\Delta t$ indicates the sampling time, $\lambda(t)$ refers to the time-based fuel consumption, $n$ is the number of samples collected during the driving cycle, $t$ is the time and $X_{t t}$ is the total distance covered during one driving cycle

$$
F_{t y}=\Delta t \frac{\left(\lambda\left(t_{0}\right)+2 \sum_{i=1}^{n-1} \lambda\left(t_{i}\right)+\lambda\left(t_{n}\right)\right)}{2 n} X_{t t} .
$$

The parameter called as engine speed at gear shifting instance refers to the speed of the engine at which the driver shifts gear. This data may reveal important information about the characteristics of the driver. For example, if the driver prefers to shift gear at high engine speeds, it is assumed as an aggressive driving style. Since this data is not directly available, it has to be extracted from engine speed data. Though, first it is required to detect gear shifting instances. Therefore, a gear shift detection algorithm is developed with the following rules. Here, it should also be mentioned that the test vehicle is not equipped with a gear position sensor. Thus, the gear stage that the vehicle is cruising is determined through the comparison of vehicle and engine speeds

1. Current gear signal must be zero (indicating neutral gear) and previous gear signal must be nonzero,

2. Gear stage signals before and after shifting should be different,

3. When the clutch pedal is pressed, gear stage signal should be zero,

4. Gear shifting process duration must be between $0.3 \mathrm{~s}$ and $3 \mathrm{~s}$.

Similar to the previous parameter (engine speed at gear shifting instance), several rules are also defined for launch time, which is the elapsed time for accelerating from $0 \mathrm{~km} / \mathrm{h}$ to $20 \mathrm{~km} / \mathrm{h}$. If the launch times for a driver are short, it is assumed that the driver has aggressive driving style. Therefore, the launch times are determined through an algorithm that is based on the following rules

1. Vehicle speed must be $0 \mathrm{kph}$ on the start of launch maneuver,

2. Vehicle must accelerate continuously until $20 \mathrm{~km} / \mathrm{h}$ speed,

3. Launch maneuver cannot exceed 10 seconds.

In order to identify driver characteristics, collected data is investigated in velocity vs. acceleration domain. Thus, corresponding data for normal drivability calibration is depicted in Figure 1 for nine drivers. Observe 
that drivers \#4, \#6 and \#8 have high average speed (more than $42 \mathrm{~km} / \mathrm{h}$ ) and acceleration (greater than 0.7 $\mathrm{m} / \mathrm{s}^{2}$ ). Thus, these drivers are identified with aggressive driving styles. Furthermore, the average velocity and acceleration values for drivers \#1 and \#2 are small; less than $38 \mathrm{~km} / \mathrm{h}$ and $0.5 \mathrm{~m} / \mathrm{s}^{2}$. Hence these drivers are assumed to have relaxed driving styles. Finally, the average velocity and acceleration values for the rest of the drivers (drivers \#3, \#5, \#7 and \#9) locate in between aggressive and relaxed limits. Hence, these drivers are assumed to have normal driving styles.

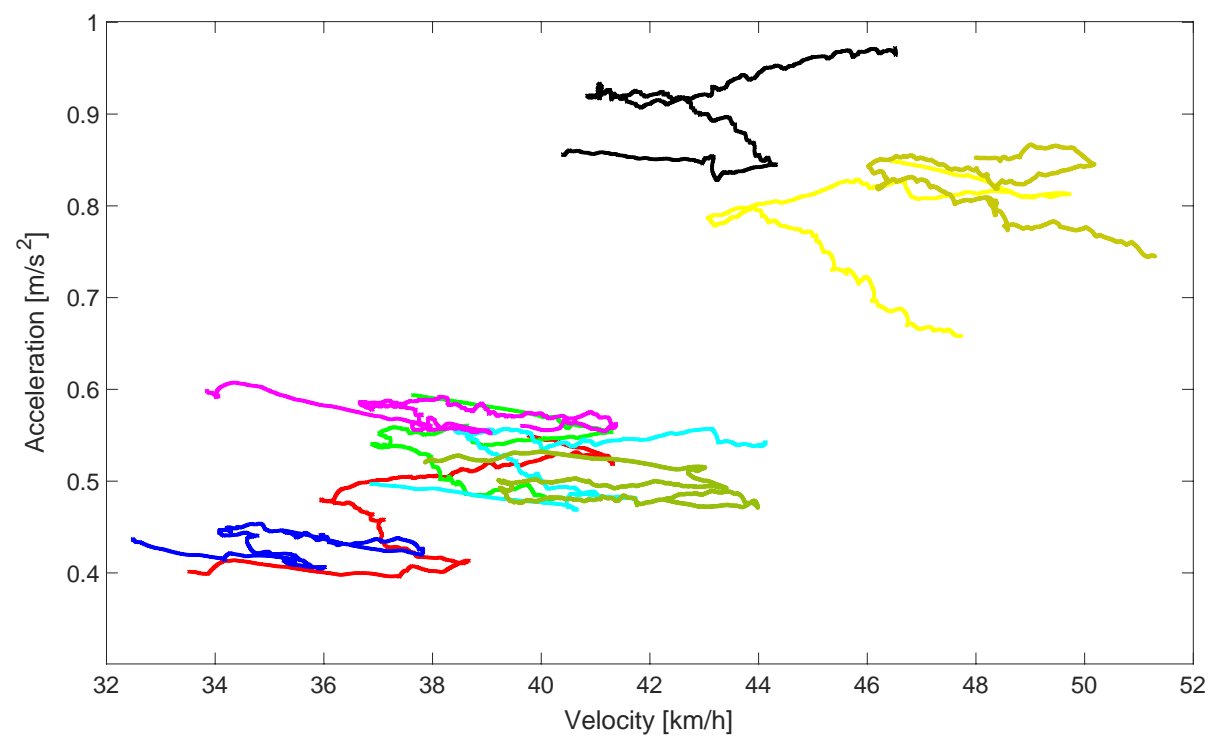

Figure 1. Velocity-acceleration traces extracted for all drivers for the tests with normal drivability calibration. Key: —, Driver \#1; _, Driver\#2; _, Driver \#3; _, Driver\#4; _, Driver \#5; —, Driver \#6; —, Driver \#7; —, Driver \#8; —, Driver \#9

In order to visualize driving styles, selected maneuvers are color-coded on the velocity time histories. Two samples of this illustration are shown in Figures 2 and 3 for drivers \#2 and \#6, respectively. Note that the color coding in these figures is as below:

1. Red: Acceleration greater than $0.4 \mathrm{~m} / \mathrm{s}^{2}$

2. Yellow: Acceleration greater than $-0.4 \mathrm{~m} / \mathrm{s}^{2}$ and less than $0.4 \mathrm{~m} / \mathrm{s}^{2}$, and the acceleration pedal position is greater than $15 \%$

3. Green: Acceleration greater than $-0.4 \mathrm{~m} / \mathrm{s}^{2}$ and less than $0.4 \mathrm{~m} / \mathrm{s}^{2}$, and the acceleration pedal position is less than $15 \%$

4. Pink: Acceleration less than $-0.4 \mathrm{~m} / \mathrm{s}^{2}$

5. Light Blue: Vehicle speed less than $2 \mathrm{~km} / \mathrm{h}$ and engine speed less than $1000 \mathrm{rpm}$.

As seen on Figures 2 and 3, the characteristics of a driver can be easily grasped. For example, the high intensity red and pink areas indicate an aggressive driving style. On the contrary, if green and yellow areas are dominant, the driving style can be identified as relaxed. Driver \#2 can be given as an example to this type of driver as evident from Figure 2. Moreover, driver \#6 seems to have aggressive driving style based on Figure 3, where there are sudden acceleration and deceleration regimes. 


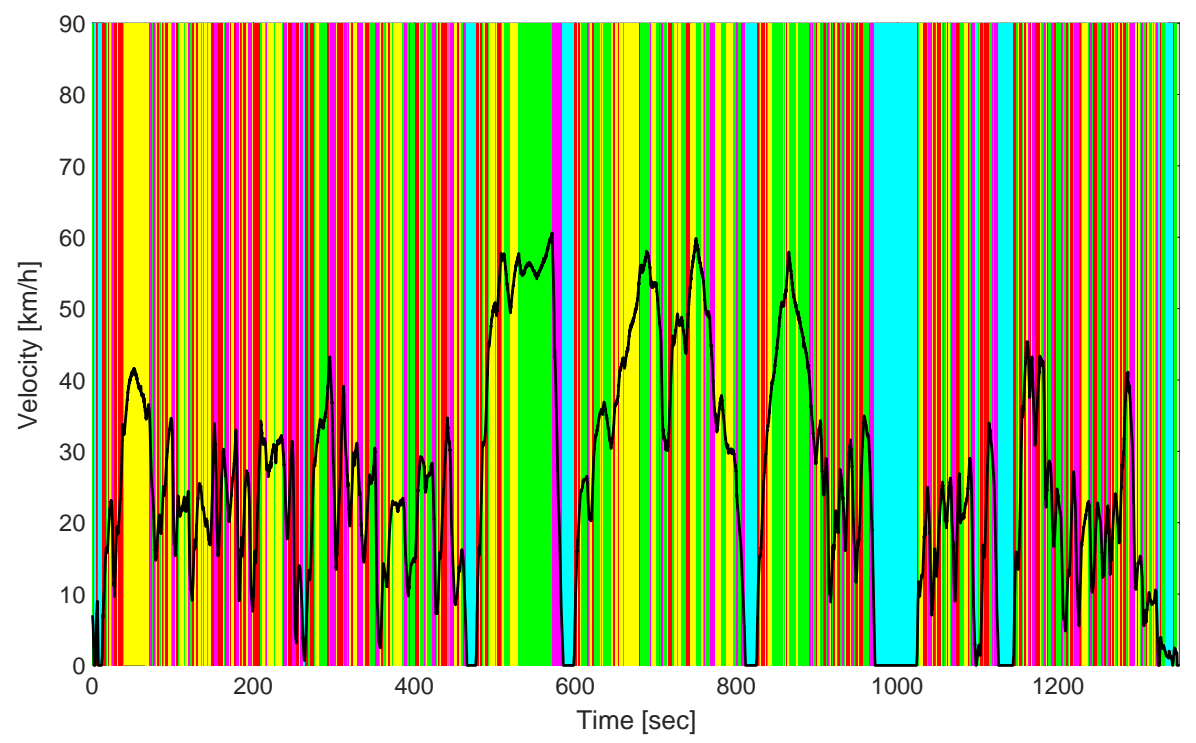

Figure 2. Velocity time history and detected maneuvers for Driver \#2 for normal vehicle calibration

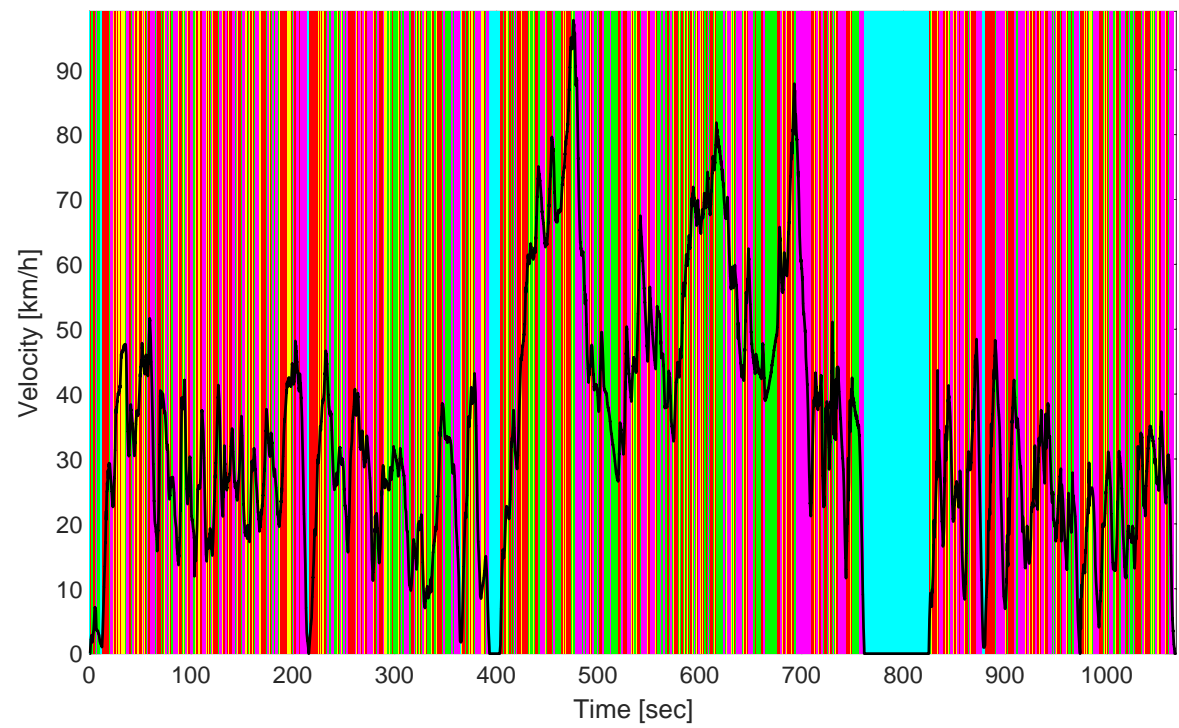

Figure 3. Velocity time history and detected maneuvers for Driver \#6 for normal vehicle calibration

\section{IMPLEMENTATION OF FUZZY LOGIC ALGORITHM FOR DRIVER CLASSIFICATION}

In order to set up the fuzzy logic structure, membership functions and rules should be identified. Thus, the thresholds for upper and lower boundaries of the seven critical parameters are determined accordingly. Since there are three different drivability calibrations, the thresholds are determined separately for all calibration types as tabulated in Table 2. Though, it is seen that the calibration type does not have a significant effect on these threshold values, i.e., same set of thresholds could be used regardless of the type of the calibration. Here, it should be noted that the data from the first nine drivers are used in order to assess the threshold values. Thus, the fuzzy logic architecture is trained with the data of these drivers. Then, the data of the last two drivers are used to test the performance of the fuzzy logic structure that is built.

The determination of the thresholds for each fuzzy logic structure are performed as follows. First, all the input parameters as listed in Table 2 are extracted from the vehicle test signals. Note that there are 27 sets of data that is obtained from 9 drivers at 3 different vehicle calibration configurations. The averages of each input parameter at all vehicle calibrations are then calculated and the distribution of each input parameter 
around the calculated average value is investigated. Based on the distribution of each input parameter for all individual vehicle calibrations, a threshold value is determined as the value that splits the membership functions as low and high. As an example, the acceleration data of all drivers collected for normal drivability calibration is shown in Figure 4. Observe that the acceleration value of $0.6 \mathrm{~m} / \mathrm{s}^{2}$ splits the responses into two categories, i.e., drivers with mean acceleration levels lower and higher than $0.6 \mathrm{~m} / \mathrm{s}^{2}$. Thus, the value $0.6 \mathrm{~m} / \mathrm{s}^{2}$ is used as the threshold of the fuzzy logic membership functions for the acceleration parameter in normal drivability calibration. This approach is applied to all parameters with all input parameters and for all different calibration values to define fuzzy logic algorithm and membership functions.

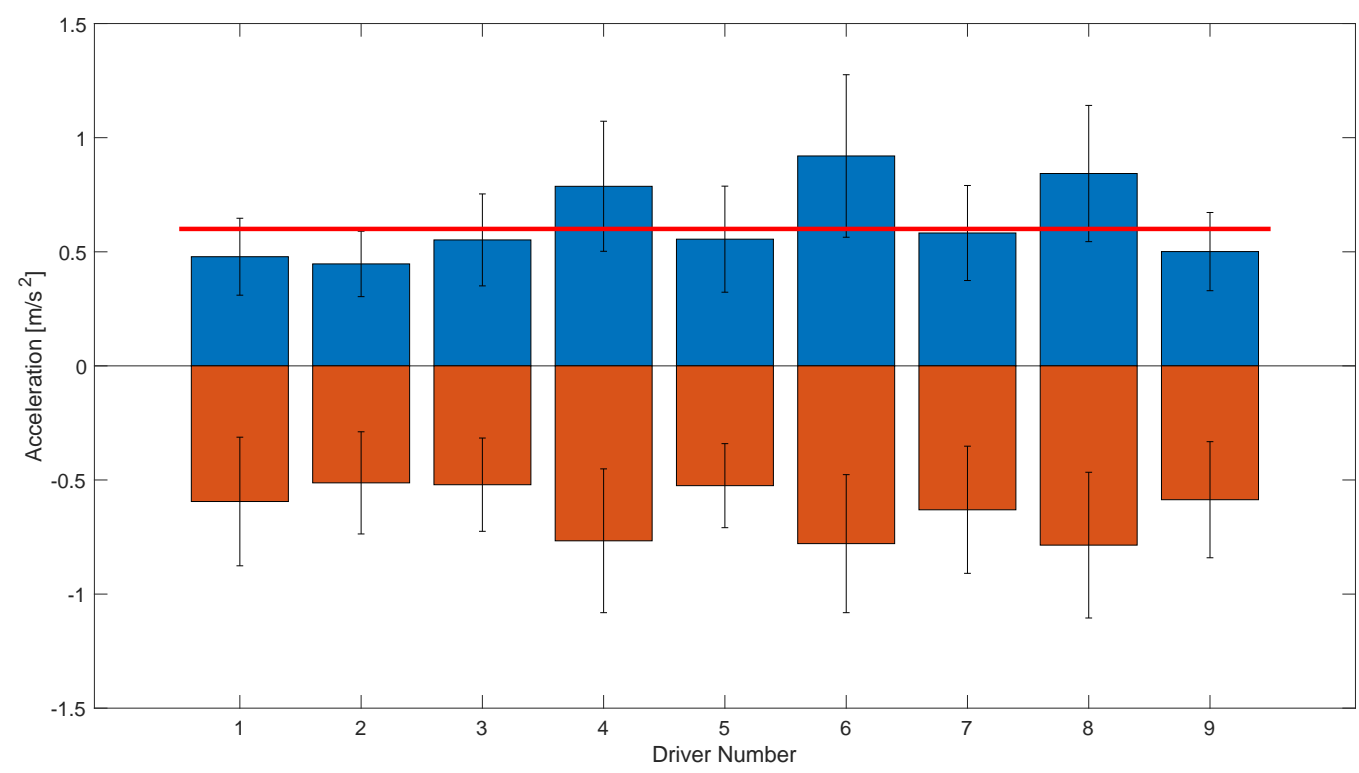

Figure 4. Positive and negative acceleration values for all drivers for the tests with normal drivability calibration. The solid red line shows the threshold value for this input parameter

Table 2. Fuzzy logic input parameters threshold values

\begin{tabular}{|c|c|c|c|}
\hline Input Parameter & Relax Calibration & Normal Calibration & Aggressive Calibration \\
\hline Fuel Consumption [1] & 3 & 3 & 3 \\
\hline Acceleration $\left[\mathrm{m} / \mathrm{s}^{2}\right]$ & 0.75 & 0.6 & 0.75 \\
\hline Average Engine Speed [rpm] & 1800 & 1750 & 1750 \\
\hline Acceleration Pedal Position [\%] & 25 & 25 & 25 \\
\hline Velocity [km/h] & 40.5 & 40 & 40.5 \\
\hline Launch time [sec] & 6.25 & 6 & 5.25 \\
\hline Engine Speed at Gear Shift [rpm] & 2250 & 2500 & 2750 \\
\hline
\end{tabular}

The fuzzy logic structure is shown in Figure 5. Note that Mamdani method is utilized for building the fuzzy logic rules. Fuzzification of driving style classification is carried out using input variables and their membership functions. The input variables are defined with two spline-based S-shaped membership functions (low and high). These membership functions for the normal calibration of the vehicle are depicted in Figure 6. For the defuzzification method, centroid approach is adopted. The output variable, which is the driving style is defined with three triangular membership functions, namely relaxed, normal and aggressive. Again, the membership functions for the output variable are given in Figure 7 for the normal calibration of the vehicle. 


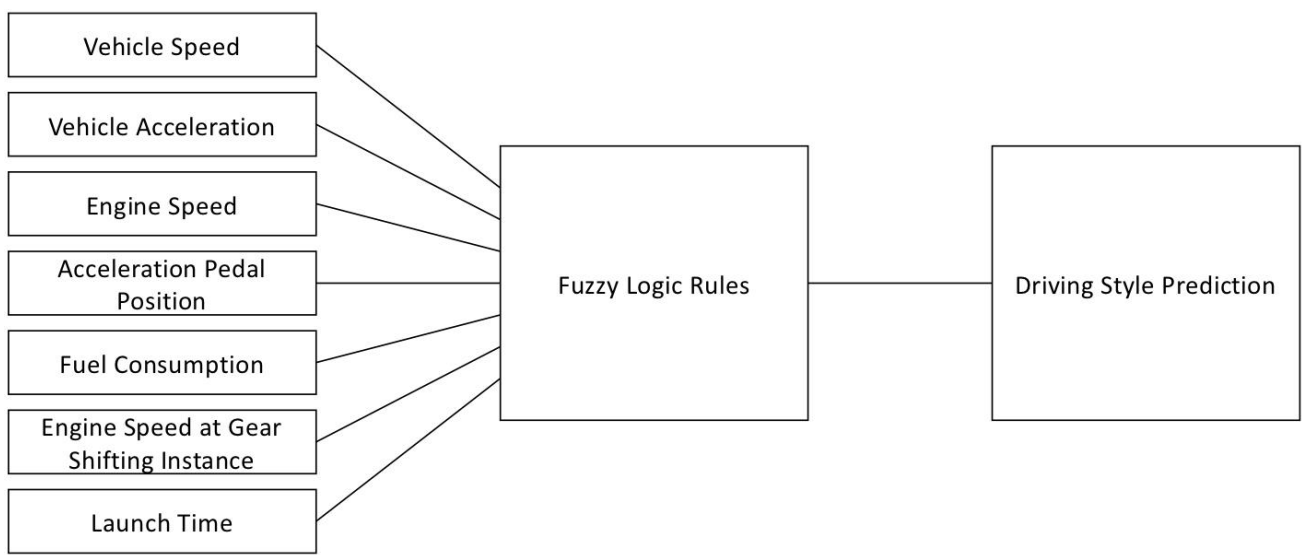

Figure 5. Fuzzy logic structure
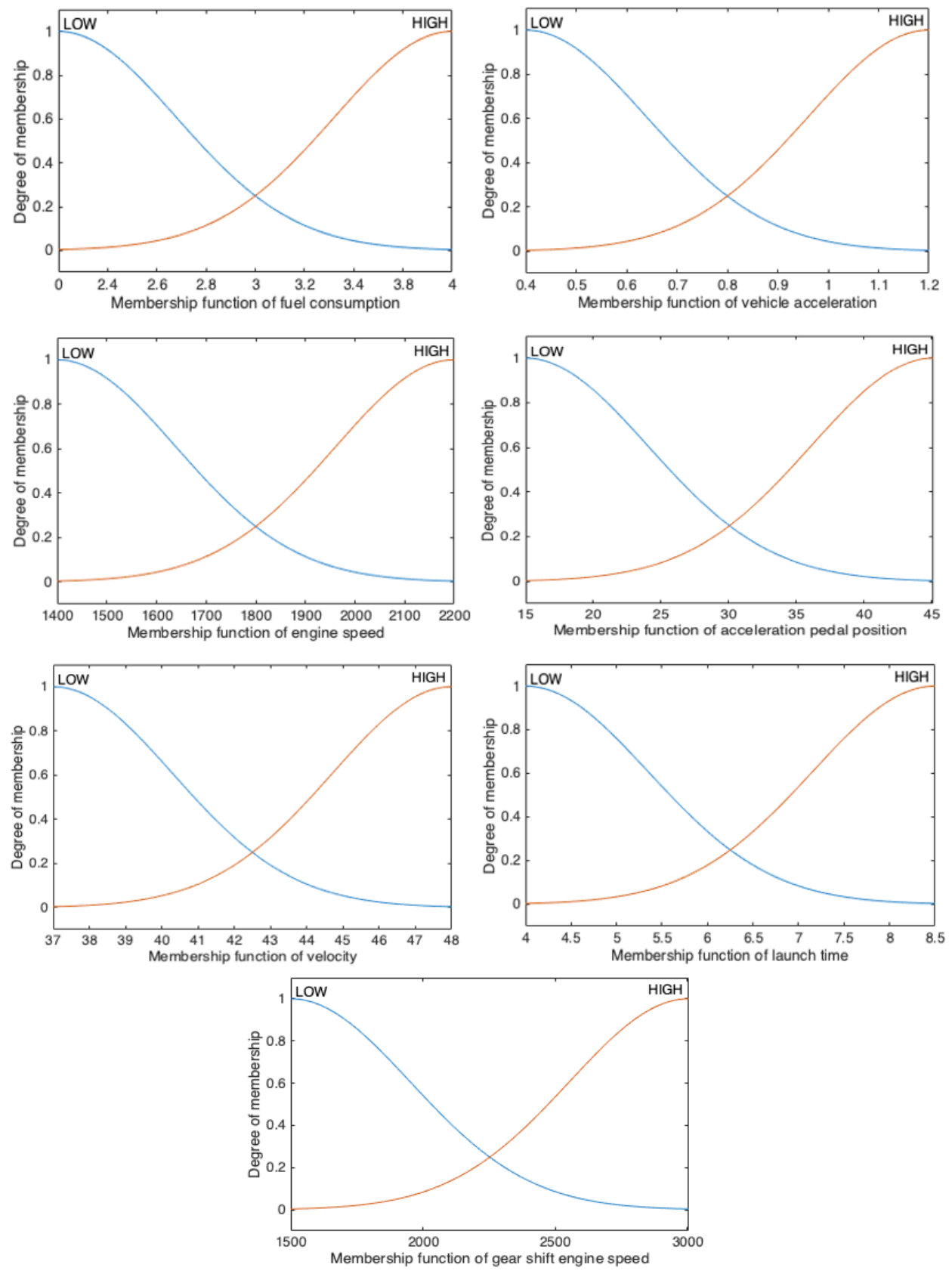

Figure 6. Spline-based S-shaped input membership functions for the normal calibration of the vehicle 


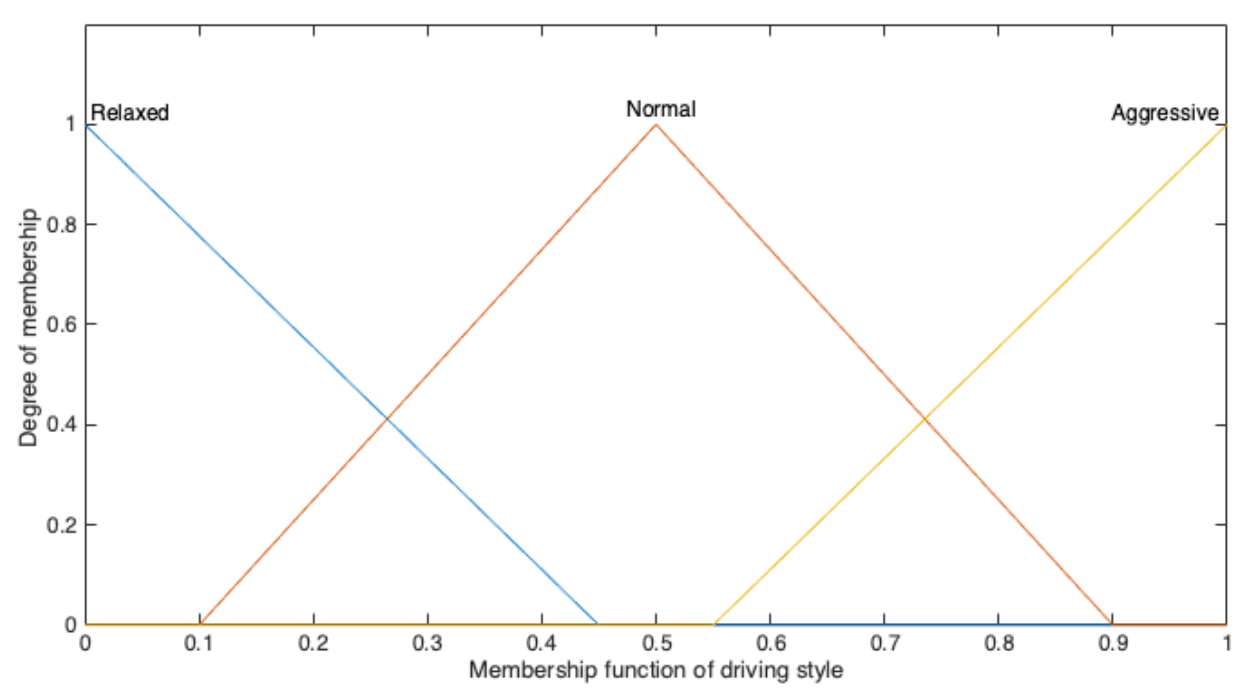

Figure 7. Triangular form-based output membership functions for the normal calibration of the vehicle

In the fuzzy logic structure developed in this study, a total of 128 rules are defined depending on the values of the critical parameters. Some of these rules are listed in Table 3. For example, if all seven parameters are located at lower levels, this driver is assumed to have a relaxed driving style (see the first line in Table 3). On the contrary, if the driver has high values for all seven input parameters, he/she is assigned with an aggressive driving style. Furthermore, if the driver has low values for three input parameters and high values for the rest, he/she is classified as a driver with normal driving style. If more than three input parameters are low, then the driver is assumed to have a relaxed driving style.

Table 3. An example of fuzzy logic rules defined

\begin{tabular}{|c|c|c|c|c|c|c|c|}
\hline $\begin{array}{c}\text { Fuel } \\
\text { Consumption }\end{array}$ & Acceleration & $\begin{array}{c}\text { Average } \\
\text { Engine } \\
\text { Speed }\end{array}$ & $\begin{array}{c}\text { Acceleration } \\
\text { Pedal } \\
\text { Position }\end{array}$ & Velocity & $\begin{array}{c}\text { Launch } \\
\text { Time }\end{array}$ & $\begin{array}{c}\text { Gear Shit } \\
\text { Engine } \\
\text { Speed }\end{array}$ & $\begin{array}{c}\text { Driving } \\
\text { Style }\end{array}$ \\
\hline Low & Low & Low & Low & Low & Low & Low & Relaxed \\
\hline High & Low & Low & Low & Low & Low & Low & Relaxed \\
\hline Low & High & Low & Low & Low & Low & Low & Relaxed \\
\hline Low & Low & High & Low & Low & Low & Low & Relaxed \\
\hline Low & Low & Low & High & Low & Low & Low & Relaxed \\
\hline Low & Low & Low & Low & High & Low & Low & Relaxed \\
\hline Low & Low & Low & Low & Low & High & Low & Relaxed \\
\hline Low & Low & Low & Low & Low & Low & High & Relaxed \\
\hline High & High & Low & Low & Low & Low & Low & Aggressive \\
\hline High & Low & High & Low & Low & Low & Low & Aggressive \\
\hline High & Low & Low & High & Low & Low & Low & Normal \\
\hline High & Low & Low & Low & High & Low & Low & Aggressive \\
\hline High & Low & Low & Low & Low & High & Low & Normal \\
\hline High & Low & Low & Low & Low & Low & High & Normal \\
\hline High & High & High & Low & Low & Low & Low & Aggressive \\
\hline High & High & Low & High & Low & Low & Low & Aggressive \\
\hline Low & High & Low & Low & High & Low & Low & Aggressive \\
\hline Low & High & Low & Low & Low & High & Low & Relaxed \\
\hline Low & High & Low & Low & Low & Low & High & Relaxed \\
\hline Low & Low & High & High & Low & Low & Low & Normal \\
\hline Low & Low & High & Low & High & Low & Low & Normal \\
\hline
\end{tabular}


All data are processed with the fuzzy logic structure by evaluating the input parameters regarding the rules defined. This process can be summarized as follows: 1) Data is collected on the vehicle three times per driver, where the drivability calibration of the vehicle is adjusted in three different configurations (relax, normal, and aggressive); 2) Data collected based on a given vehicle calibration is processed with the corresponding fuzzy logic algorithm (relax, normal, and aggressive); 3) Driving style of the driver is evaluated based on the driving indexes produced by each fuzzy logic algorithm. This decision-making process is shown in Figure 8.

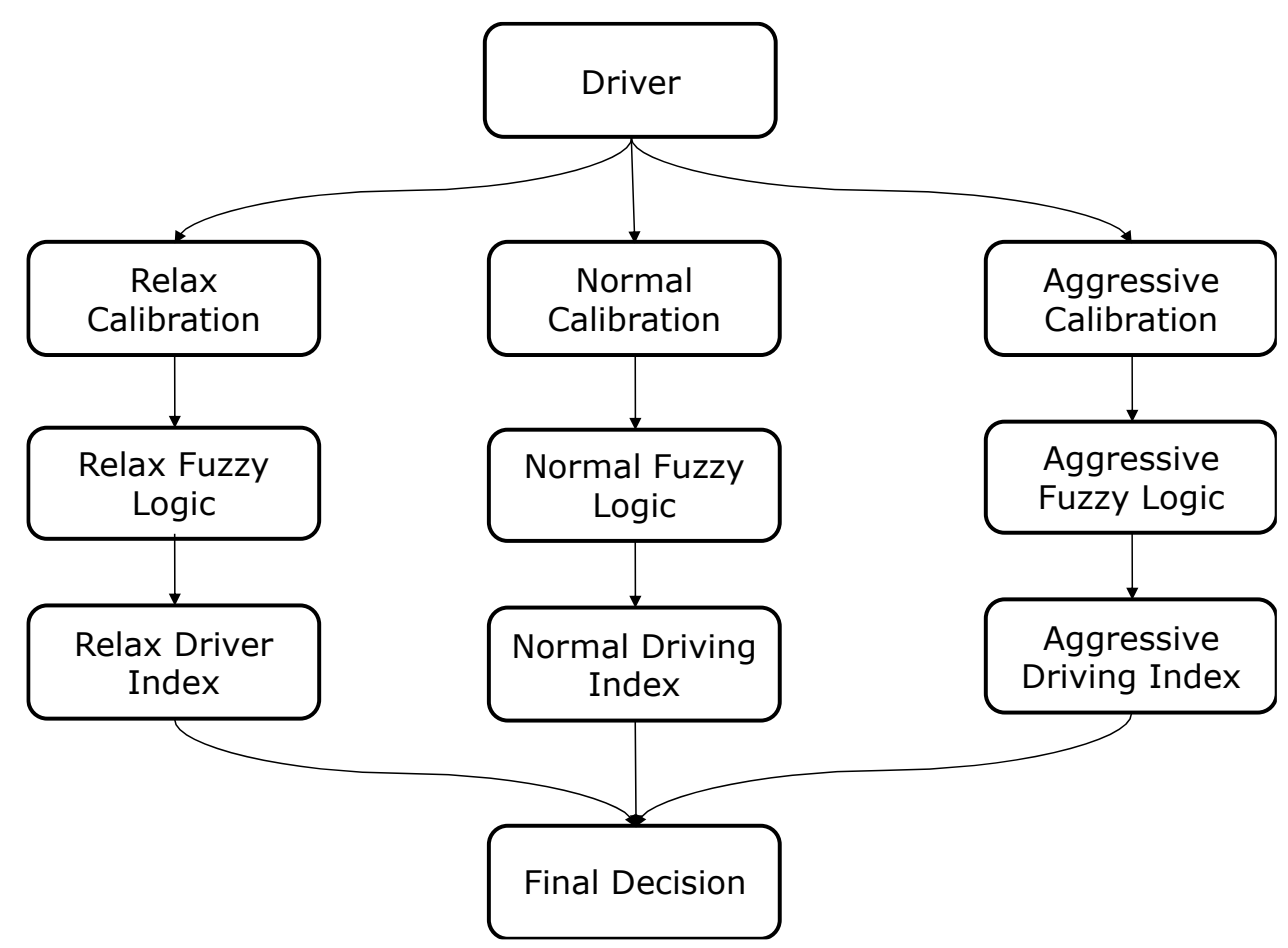

Figure 8. General decision-making flowchart for driver evaluation

Each fuzzy logic structure produces a scalar, which is called the driving index, in the range $0-1$ as an output. The driving indexes obtained based on the collected data are tabulated in Table 4. Driving indexes are then used to identify the characteristics of the corresponding driver, i.e., higher driving index increases the aggressiveness of the driving style. Furthermore, the limits for the driving index are defined as follows: 1) relaxed driving style for the range of $0-0.4 ; 2$ ) normal driving style for the range of $0.4-0.6$; and 3 ) aggressive driving style for the range of $0.6-1$.

Observe from Table 4 that, driving styles are predicted for all drivers and drivability calibrations. Thus, each driver has assigned with different driving styles based on the drivability calibration of the vehicle. This indicates the effect of drivability calibration on the driver response, which may alter from driver to driver. For example, the driving styles of drivers \#3, \#5 and \#9 are identified as normal with normal drivability calibration. However, the driving style of these drivers become relaxed when the drivability calibration of the vehicle is changed to aggressive. This can be explained with extra precautions taken by these drivers while driving a vehicle with aggressive drivability calibration. On the contrary, drivers \#3 and \#9 easily adapt to relaxed drivability calibration. In the meantime, drivers \#4 and \#8 represent aggressive driving style regardless of the drivability calibration. Thus, the drivability calibration does not affect the driving style of drivers \#4 and \#8. Similarly, the driving style of driver \#1 is identified as normal regardless of the drivability calibration of the vehicle.

The final decision on the driving style of a driver is then given based on the arithmetic mean of the driving indexes obtained from each fuzzy logic structure, which is also tabulated on Table 4. Therefore, drivers \#3 and \#9 are classified with relaxed driving style, drivers \#1, \#2 and \#5 are assumed to have a normal driving style and drivers \#4, \#6, \#7 and \#8 have an aggressive driving style. 
Table 4. Fuzzy logic results for the training set

\begin{tabular}{|c|c|c|c|c|c|c|c|c|}
\hline \multirow{3}{*}{$\begin{array}{c}\text { Driver } \\
\#\end{array}$} & \multicolumn{9}{|c|}{ Relax } & \multicolumn{2}{c|}{ Normal } & \multicolumn{2}{c|}{ Aggressive } & \multicolumn{2}{c|}{ Final Decision } \\
\cline { 2 - 9 } & $\begin{array}{c}\text { Driving } \\
\text { Style }\end{array}$ & $\begin{array}{c}\text { Driving } \\
\text { Index }\end{array}$ & $\begin{array}{c}\text { Driving } \\
\text { Style }\end{array}$ & $\begin{array}{c}\text { Driving } \\
\text { Index }\end{array}$ & $\begin{array}{c}\text { Driving } \\
\text { Style }\end{array}$ & $\begin{array}{c}\text { Driving } \\
\text { Index }\end{array}$ & $\begin{array}{c}\text { Driving } \\
\text { Style }\end{array}$ & $\begin{array}{c}\text { Driving } \\
\text { Index }\end{array}$ \\
\hline 1 & Normal & 0.452 & Normal & 0.487 & Normal & 0.423 & Normal & 0.454 \\
\hline 2 & Normal & 0.411 & Relaxed & 0.368 & Normal & 0.459 & Normal & 0.413 \\
\hline 3 & Relaxed & 0.358 & Normal & 0.453 & Relaxed & 0.388 & Normal & 0.400 \\
\hline 4 & Aggressive & 0.852 & Aggressive & 0.677 & Aggressive & 0.844 & Aggressive & 0.791 \\
\hline 5 & Normal & 0.408 & Normal & 0.445 & Relaxed & 0.385 & Normal & 0.413 \\
\hline 6 & Normal & 0.568 & Aggressive & 0.816 & Aggressive & 0.807 & Aggressive & 0.730 \\
\hline 7 & Normal & 0.522 & Aggressive & 0.725 & Aggressive & 0.633 & Aggressive & 0.627 \\
\hline 8 & Aggressive & 0.653 & Aggressive & 0.853 & Aggressive & 0.740 & Aggressive & 0.749 \\
\hline 9 & Relaxed & 0.259 & Normal & 0.407 & Relaxed & 0.223 & Relaxed & 0.296 \\
\hline
\end{tabular}

\section{PERFORMANCE ASSESSMENT OF THE FUZZY LOGIC ALGORITHM}

In order to understand the effect of threshold values on the decision given by fuzzy logic algorithm, threshold values tabulated in Table 2 are varied by $\pm 10 \%$ and data is again run through the fuzzy logic architecture. Though, the results of only two parameters, namely launch time and engine speed at gear shift are presented in Table 5. Note that, data in Table 5 represents the final decisions, thus needs to be compared with the last two columns of Table 4. In overall, it is observed that final decisions given by fuzzy logic algorithm do not change with respect to threshold values. By the inspection of Table 5, one can see that the decisions for driver \#5 (for 10\% increase at engine speed at gear shift) and driver \#7 (for 10\% reduction at launch time) are changed. The driving indexes for these cases are 0.396 and 0.599 , respectively. As seen, these driving index values are very close to the limits of driving styles, i.e. 0.4 and 0.6. Furthermore, a change in the driving style of driver \#3 is observed for $10 \%$ increase at engine speed at gear shift. Besides these three cases, all the decisions given by fuzzy logic algorithm remain the same as with the nominal threshold values.

Table 5. Effect of fuzzy logic threshold values on decision making

\begin{tabular}{|c|c|c|c|c|c|c|c|c|}
\hline \multirow{4}{*}{$\begin{array}{c}\text { Driver } \\
\#\end{array}$} & \multicolumn{2}{|c|}{$\begin{array}{c}10 \% \text { Increase at } \\
\text { Launch Time }\end{array}$} & \multicolumn{2}{c|}{$\begin{array}{c}10 \% \text { Reduction at } \\
\text { Launch Time }\end{array}$} & \multicolumn{2}{c|}{$\begin{array}{c}10 \% \text { Increase at } \\
\text { Engine Speed at Gear } \\
\text { Shift }\end{array}$} & \multicolumn{2}{c|}{$\begin{array}{c}10 \% \text { Reduction at } \\
\text { Engine Speed at Gear } \\
\text { Shift }\end{array}$} \\
\cline { 2 - 9 } & $\begin{array}{c}\text { Driving } \\
\text { Style }\end{array}$ & $\begin{array}{c}\text { Driving } \\
\text { Index }\end{array}$ & $\begin{array}{c}\text { Driving } \\
\text { Style }\end{array}$ & $\begin{array}{c}\text { Driving } \\
\text { Index }\end{array}$ & $\begin{array}{c}\text { Driving } \\
\text { Style }\end{array}$ & $\begin{array}{c}\text { Driving } \\
\text { Index }\end{array}$ & $\begin{array}{c}\text { Driving } \\
\text { Style }\end{array}$ & $\begin{array}{c}\text { Driving } \\
\text { Index }\end{array}$ \\
\hline 1 & Normal & 0.469 & Normal & 0.475 & Normal & 0.447 & Normal & 0.484 \\
\hline 2 & Normal & 0.400 & Normal & 0.442 & Normal & 0.410 & Normal & 0.467 \\
\hline 3 & Normal & 0.410 & Normal & 0.402 & Relaxed & 0.385 & Normal & 0.406 \\
\hline 4 & Aggressive & 0.741 & Aggressive & 0.745 & Aggressive & 0.742 & Aggressive & 0.741 \\
\hline 5 & Normal & 0.417 & Normal & 0.408 & Relaxed & 0.396 & Normal & 0.415 \\
\hline 6 & Aggressive & 0.652 & Aggressive & 0.657 & Aggressive & 0.654 & Aggressive & 0.653 \\
\hline 7 & Aggressive & 0.605 & Normal & 0.599 & Aggressive & 0.604 & Aggressive & 0.606 \\
\hline 8 & Aggressive & 0.725 & Aggressive & 0.726 & Aggressive & 0.714 & Aggressive & 0.721 \\
\hline 9 & Relaxed & 0.369 & Relaxed & 0.339 & Relaxed & 0.329 & Relaxed & 0.378 \\
\hline
\end{tabular}

As mentioned before, only the data of the first nine drivers are used in order to develop the fuzzy logic approach-based driver classification algorithm. In other words, data from the first nine drivers are used to train the fuzzy logic structure. In order to assess the performance of this approach, two other drivers are chosen and driving tests are again performed with the same vehicle calibrations. Data collected from these tests are run through the developed fuzzy logic-based driver classification algorithm and the results are tabulated in Table 6 . As seen on Table 6, driver \#10 shows a normal driving behavior and driver \#11 exhibits an aggressive driving style. 
Table 6. Fuzzy logic results for the drivers \#10 and \#11

\begin{tabular}{|c|c|c|c|c|c|c|c|c|}
\hline \multirow{3}{*}{$\begin{array}{c}\text { Driver } \\
\#\end{array}$} & \multicolumn{9}{|c|}{ Relax } & \multicolumn{2}{c|}{ Normal } & \multicolumn{2}{c|}{ Aggressive } & \multicolumn{2}{c|}{ Final Decision } \\
\cline { 2 - 9 } & $\begin{array}{c}\text { Driving } \\
\text { Style }\end{array}$ & $\begin{array}{c}\text { Driving } \\
\text { Index }\end{array}$ & $\begin{array}{c}\text { Driving } \\
\text { Style }\end{array}$ & $\begin{array}{c}\text { Driving } \\
\text { Index }\end{array}$ & $\begin{array}{c}\text { Driving } \\
\text { Style }\end{array}$ & $\begin{array}{c}\text { Driving } \\
\text { Index }\end{array}$ & $\begin{array}{c}\text { Driving } \\
\text { Style }\end{array}$ & $\begin{array}{c}\text { Driving } \\
\text { Index }\end{array}$ \\
\hline 10 & Normal & 0.548 & Normal & 0.482 & Normal & 0.430 & Normal & 0.487 \\
\hline 11 & Aggressive & 0.701 & Aggressive & 0.768 & Aggressive & 0.709 & Aggressive & 0.726 \\
\hline
\end{tabular}

In order to validate the results of the fuzzy logic algorithm, data from drivers \#10 and \#11 are further investigated. For example, the average acceleration pedal position of driver \#10 is around 20\%, whilst it is over 30\% for driver \#11. Furthermore, the average fuel consumption of driver \#10 is around 2.41 , whilst the average fuel consumption for driver \#11 is over 3.4 1. As another parameter, the average vehicle speed for drivers \#10 and \#11 are $37 \mathrm{~km} / \mathrm{h}$ and $45 \mathrm{~km} / \mathrm{h}$, respectively. As evident from these results, the fuzzy logic results show similar trend with these key parameters. Thus, it is concluded that the fuzzy logic structure developed with the training set successfully predicts the driver characteristics of other drivers that do not belong to the training set.

\section{RESULTS AND CONCLUSION}

In this study, an experimental procedure is developed and experiments are conveyed in order to identify the driving styles of different individuals. Accordingly, vehicle tests are performed with eleven different drivers at three different drivability calibrations of the test vehicle. Thus, a total of 33 tests are run and data are collected mainly through the CAN bus interface of the test vehicle. First, seven important parameters are identified that are assumed to be closely related with the driving style of the drivers. These parameters are then analyzed from the collected data in order to obtain critical threshold values that are necessary for fuzzy logic rules. Though, only the data of first nine drivers are used in order to determine these threshold values. In the fuzzy logic structure, a total of 128 rules are defined, and the driver classification is performed for all three drivability calibrations. Finally, drivers are assigned a scalar value by the corresponding fuzzy logic algorithm as identified as driving index, and the driving styles of all drivers are predicted. Based on these driving indexes, it is observed that the drivability calibration can be effective on the driving style of the driver. In order to investigate the effect of threshold values on driving style decisions, the threshold values of seven important parameters are varied by $\pm 10 \%$ and new decisions are taken from the fuzzy logic structure with these altered threshold values. It is observed that, the change in final decision is minimal with respect to a change in threshold value. Thus, it is concluded that there is no significant effect of threshold values on the driving style decision. Further, test data of the other two drivers are used in order to assess the performance of the driver classification algorithm. Comparing the fuzzy logic results with the driving data shows that the fuzzy logic algorithm successfully predicts the driver behavior even for the drivers that are kept out of the training set. In conclusion, a prediction algorithm with a focus on driving characteristics, which establishes fuzzy logic structure, is successfully developed in this study. Even though it is off the scope, this approach can be implemented on a vehicle as a decision-making process for automated prediction. The in-situ evaluation of the input parameters as described in this study can yield to a driving index that can be used to decide on the driver behavior. Though, this requires the use of a single fuzzy logic structure, i.e. one fuzzy logic algorithm irrespective of the vehicle calibration. Hence, the vehicle can alter its drivability characteristics based on the driving style of the driver.

\section{ACKNOWLEDGEMENT}

Support from AVL Turkey is gratefully acknowledged by the first author.

\section{CONFLICTS OF INTEREST}

No conflict of interest was declared by the authors. 


\section{REFERENCES}

[1] Murphey, Y.L., Milton, R., Kiliaris, L., “Driver's style classification using jerk analysis”, IEEE Workshop on Computational Intelligence in Vehicles and Vehicular Systems, Nashville, TN, USA, (2009).

[2] Sun, B., Deng, W., Wu, J., Li, Y., Zhu, B., Wu, L., "Research on the classification and identification of driver's driving style", $10^{\text {th }}$ International Symposium on Computational Intelligence and Design, Hangzhou, China, 28-32, (2017).

[3] Lopez, J.O., Pinilla, A.C.C., "Driver Behavior Classification Model based on an Intelligent Driving Diagnosis System", $15^{\text {th }}$ International IEEE Conference on Intelligent Transportation System, Anchorage, AK, USA, 894-899, (2012).

[4] Sundbom, M., Falcone, P., Sjöberg, J., "Online Driver Behavior Classification Using Probabilistic ARX Models", $16^{\text {th }}$ International IEEE Annual Conference on Intelligent Transportation Systems, The Hague, Netherlands, 1107-1112, (2013).

[5] Ciceo, S., Mollet, Y. Sarrazin, M., Gyselinck, J., Van der Auwarer, H., Martiş, C., "Model-Based Design and Testing for Electric Vehicle Driveability Analysis", $16^{\text {th }}$ International Conference on Environment and Electrical Engineering, Florence, Italy, 1-4, (2016).

[6] Ping, P., Qin, W., Xu, Y., Miyajima, C., Takeda, K., "Impact of Driver Behavior on Fuel Consumption: Classification, Evaluation and Prediction Using Machine Learning”, IEEE Access, 7: 78515-78532, (2019).

[7] Zfnebi, K., Soussi, N., Tikito, K., "Driver Behavior Quantitative Models: Identification and Classification of Variables", International Symposium on Networks, Computers and Communications, Marrakech, Morocco, 1-6, (2017).

[8] Zheng, Y., Chase, R.T., Elefteriadou, L., Sisiopiku, V., Schroeder, B., "Driver Types and Their Behaviors Within a High Level of Pedestrian Activity Environment", Transportation Letters, 9(1): 1-11, (2017).

[9] Bernardi, M.L., Cimitile, M., Martinelli, F., Mercaldo, F., "Driver Identification: a Time Series Classification Approach", International Joint Conference on Neural Networks, Rio de Janeiro, Brazil, 1-7, (2018).

[10] Zhang, D., "Vehicle Parameters Estimation and Driver Behavior Classification for Adaptive Shift Strategy of Heavy Duty Vehicles", Ph.D. Thesis, Clemson University, SC, USA, (2017).

[11] Langari, R., Won, J.S., "Intelligent Energy Management Agent for a Parallel Hybrid Vehicle Part I: System Architecture and Design Identification”, IEEE Transactions on Vehicular Technology, 54(3): 925-934, (2005).

[12] Cheng, Z.J., Jeng, L.W., Li, K., "Behavioral Classification of Drivers for Driving Efficiency Related ADAS Using Artificial Neural Network", International Conference on Advanced Manufacturing, Yunlin, Taiwan, 173-176, (2018).

[13] Fernandez, S., Ito, T., "Driver Classification for Intelligent Transportation Systems using Fuzzy Logic", 19th International Conference on Intelligent Transportation Systems, Rio de Janeiro, Brazil, 1212-1216, (2016). 
[14] Cheung, E., Bera, A., Manocha, D., "Efficient and Safe Vehicle Navigation Based on Driver Behavior Classification", Conference on Computer Vision and Pattern Recognition Workshop, Salt Lake City, UT, USA, 1024-1031, (2018).

[15] Lin, N., Zong, C., Tomizuka, M., Song, P., Zhang, Z., Li, G., "An Overview on Study of Identification of Driver Behavior Characteristics for Automotive Control", Mathematical Problems in Engineering, 2014: 1-15, (2014). 